\title{
EYELID RECONSTRUCTION IN OPHTHALMIC SURGICAL PRACTICE
}

\author{
Zornitsa Zlatarova, Binna Nenkova \\ Department of Ophthalmology and Visual Sciences, Faculty of Medicine, \\ Medical University of Varna
}

\begin{abstract}
INTRODUCTION: Eyelid reconstruction is not implemented very often in ophthalmic surgical practice. Numerous surgical procedures exist, and the surgeon's experience is one of the leading factors for the choice of a technique.

AIM: The aim of this article is to study the causes and frequency of eyelid surgeries at the Specialized Eye Hospital for a five-year period and to evaluate the chosen surgical approach in relation to patients' disease.

MATERIALS AND METHODS: A retrospective study was conducted on all patients who underwent eyelid surgery in the hospital for the study period (2011-2015). Detailed information was collected on demographic data, clinical details for the diagnosis, histological results, and type of surgery.

RESULTS: A total of 692 reconstructive eyelid surgeries were performed, which represents $5.63 \%$ of all surgeries in the hospital for the study period. The most common cause of planed eyelid surgery was tumor excision (50.8\%) and the used reconstructive procedures were: direct closure in $78.3 \%$ of cases, skin flap transposition $-15.5 \%$, Hughes procedure $-3.1 \%$, full-thickness skin graft $-2.7 \%$, and Cutler-Beard procedure - $0.4 \%$. Entropion was diagnosed in $18.5 \%$, ectropion $-13.0 \%$, dermatochalasis $-9.1 \%$, and ptosis $-8.5 \%$ of the planned surgeries. The most frequently used technique for entropion repair was the Quickert procedure $-44.7 \%$ and for ectropion repair this was the Bick procedure $-59.1 \%$. Ptosis was acquired in $\mathbf{6 2 . 8 \%}$ of cases, and the most frequently used technique was aponeurosis surgery $-\mathbf{5 7 . 2 \%}$.

CONCLUSION: Eyelid reconstruction is an important branch of oculoplastic surgery. We found that tumor excision was the most common reason for planned eyelid surgeries. In recent years, the number of blepharoplasties has increased markedly.
\end{abstract}

Keywords: eyelid surgery, ectropion, entropion, ptosis, eyelid tumors, blepharoplasty

Address for correspondence:

Zornitsa Zlatarova

Faculty of Medicine

Medical University of Varna

55 Marin Drinov St

9002 Varna

e-mail: zzlatarova@abv.bg

Received: September 19, 2020

Accepted: December 6, 2020

\section{INTRODUCTION}

Different causes throughout the person's life might lead to a change in the position and function of the eyelids, thus requiring surgical correction. The most common among them are age-related tissue changes, horizontal lid laxity, ligament dehiscence resulting in involutional entropion, ectropion, ptosis, and dermatochalasis formation. Jacobs LC et al. reported an overall prevalence of sagging 
eyelids among individuals 45 years and older in the Netherlands to be $16.3 \%$, more common among men (19.0\%) than in women (14.4\%) (1). They found many non-genetic risk factors for sagging eyelids, including age, high body mass index, lighter skin color, smoking, male gender, and heritability. Damasceno RW et al. evaluated 24565 elderly people and found the prevalence of involutional entropion to be $2.1 \%$ and that of involutional ectropion - $2.9 \%$, with involutional entropion being more prevalent in women and involutional ectropion more prevalent among men (2). The Blue Mountains Eye Study evaluated 3654 people aged between 49 and 97 years, and found that ectropion prevalence was $3.9 \%$, higher in men (5.1\%) than in women (3.0\%) (3). The prevalence of involutional ectropion and entropion increases with the patient's age $(2,3)$.

Different studies report different prevalence of congenital and acquired ptosis. Lee et al., in their hospital-based study in Korea, found congenital ptosis in $78 \%$ of cases (4). In contrast, in Chicago, Lim et al., also in a hospital-based study, reported that the most common type of ptosis was aponeurotic ptosis (5). Levator muscle starts thinning and loses muscle tone with age; disinsertion and dehiscence of the levator aponeurosis are also common in elderly people, and all these conditions result in involutional ptosis formation (6).

Trauma and post-traumatic cicatrices, neurological diseases, like pareses and paralyses of $\mathrm{n}$. fascialis and n. oculomotorius, also lead to changes in the eyelid position. Eyelid tumors are more common among people above 60 years of age and the most common neoplasms in ophthalmic practice treated with eyelid surgery.

In Bulgaria, where more than $21 \%$ of the population is above 65 , and more than $24 \%$ of women are above 65 years of age, the need of reconstructive eyelid surgery is expected to increase in the next years (7).

In the framework of an increasing demand for plastic and aesthetic surgery, the number of descriptive epidemiological studies analyzing the main reconstructive eyelid surgeries in relation to the characteristics of the patients and their diseases is limited.

\section{AIM}

The aim of this study was to evaluate the causes and frequency of eyelid surgeries performed in the Specialized Eye Hospital - Varna for the five-year period and the chosen surgical approach in relation to patients' diseases.

\section{MATERIALS AND METHODS}

A retrospective study was conducted over a 5-year period (2011-2015) including all of the patients who underwent eyelid surgery (excluding chalazion excision) at the Specialized Eye Hospital - Varna, providing services not only to the population of Varna region, but to the whole region of Eastern Bulgaria. Detailed information was collected on demographic data, including age, sex, resident status and clinical details for the diagnosis, histological result and type of surgery. It was summarized with descrip-

Table 1. Diagnosis leading to eyelid surgeries for the five-year period

\begin{tabular}{|lc|c|c|c|c|c|}
\hline \multirow{2}{*}{ Type of diagnosis } & 2011 & 2012 & 2013 & 2014 & 2015 & Total \\
\cline { 2 - 6 } & $\mathrm{n}(\%)$ & $\mathrm{n}(\%)$ & $\mathrm{n}(\%)$ & $\mathrm{n}(\%)$ & $\mathrm{n}(\%)$ & $\mathrm{n}(\%)$ \\
Trauma & $33(25.8)$ & $40(35.7)$ & $31(21.4)$ & $37(24.8)$ & $43(27.2)$ & $184(26.6)$ \\
Benign tumors & $26(20.3)$ & $21(18.6)$ & $38(26.2)$ & $50(33.6)$ & $35(22.2)$ & $170(24.6)$ \\
Malignant tumors & $23(17.9)$ & $12(10.7)$ & $17(11.7)$ & $20(13.4)$ & $16(10.1)$ & $88(12.7)$ \\
Entropion & $16(12.5)$ & $11(9.8)$ & $17(11.7)$ & $16(10.7)$ & $34(21.5)$ & $94(13.6)$ \\
Ectropion & $12(9.4)$ & $13(11.6)$ & $22(15.2)$ & $10(6.7)$ & $9(5.7)$ & $66(9.5)$ \\
Ptosis & $11(8.6)$ & $9(8.03)$ & $14(9.7)$ & $3(2.0)$ & $6(3.8)$ & $43(6.2)$ \\
Dermatochalasis & $7(5.5)$ & $6(5.36)$ & $6(4.1)$ & $13(8.7)$ & $14(8.9)$ & $46(6.6)$ \\
Floppy eyelid & $0(0.0)$ & $0(0.0)$ & $0(0.0)$ & $0(0.0)$ & $1(0.6)$ & $1(0.1)$ \\
Total eyelid & $128(100.0)$ & $112(100,0)$ & $145(100,0)$ & $149(100.0)$ & $158(100.0)$ & $692(100.0)$ \\
surgeries & & & & & \\
\hline
\end{tabular}


Zornitsa Zlatarova, Binna Nenkova

tive statistical methods - qualitative variables were presented as percentages and quantitative variables with mean and SD.

Ethical approval for the study was obtained from the Ethics Committee of the Specialized Eye Hospital - Varna.

\section{RESULTS}

A total of 692 reconstructive eyelid surgeries were performed for the study period, including trauma, ectropion, entropion, ptosis, dermatochalasis, and tumors. These operations represented 5.63\% of all surgeries of the eyeball and eye adnexa for the study period (mean 2456 operations per year). Diagnosis leading to eyelid surgeries for the study period are presented in Table 1.

Excluding trauma cases (184, or $26.58 \%$, for the five-year period), which were treated as emergencies, the planned surgeries for eyelid malposition and tumor excision were $4.14 \%$ of all performed surgeries at the hospital for the studied 5-year period. The mean age of these patients $(n=508)$ was 61.6 (SD 17.42) years, where male patients presented $43.3 \%$ of all cases. The most common reason for planned surgery was tumor excision (Fig. 1).

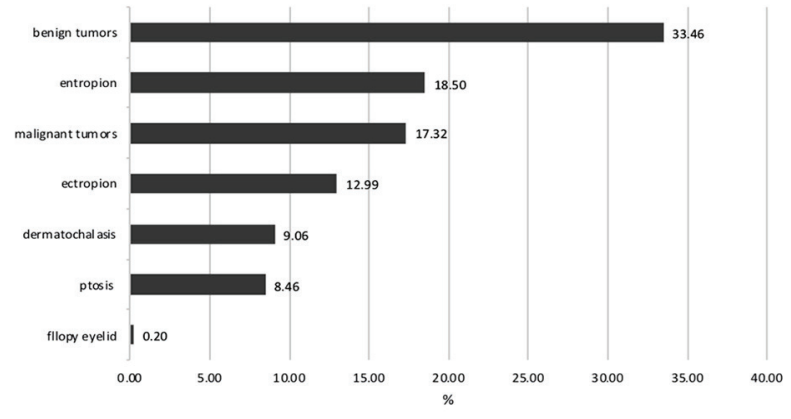

Fig. 1. Distribution of planned eyelid reconstructive surgeries by diagnosis $(n=508)$

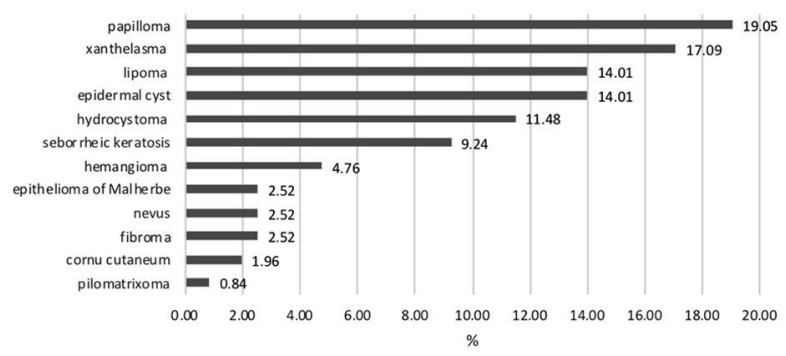

Fig. 2. Histological type of benign eyelid tumors
Table 2. Demographics of patients who underwent planned eyelid surgery by diagnosis

\begin{tabular}{lcccc}
\hline Type of Diagnosis & $\mathrm{n}$ & $\begin{array}{c}\text { Mean Age } \\
(\mathrm{SD})\end{array}$ & \% Male \\
\hline Benign tumors & 170 & $55.0(16.36)$ & 38.8 \\
Malignant tumors & 88 & $67.5(12.06)$ & 39.8 \\
Entropion & 94 & $71.0(11.67)$ & 45.7 \\
Ectropion & 66 & $71.8(11.40)$ & 71.2 \\
Ptosis & 43 & $48.9(28.52)$ & 53.5 \\
Dermatochalasis & 46 & $53.3(9.90)$ & 10.9 \\
Floppy eyelid & 1 & 49 & 100 \\
Total & 508 & $61.7(17.41)$ & 43.3 \\
\hline
\end{tabular}

Demographic data of patients who underwent planned eyelid surgery are presented in Table 2.

The total number of benign eyelid tumors was 170. The most common was papilloma - $19 \%$ of cases (Fig. 2). The surgical procedure used most often after a benign tumor excision was direct closure - in $90 \%$ of the cases, and in 10\% skin flap transposition was needed.

The total number of malignant eyelid tumors was 88 . The most common histological type was basal cell carcinoma (BCC) $-85.2 \%$ of the cases, squamous cell carcinoma (SCC) present in $9.1 \%$, sebaceous carcinoma $-3.4 \%$, Merkell cell carcinoma $1.1 \%$, and trichilemmal carcinoma $-1.1 \%$. Lower lid tumor localization was found in $63.6 \%$ of the cases, upper lid $-18.2 \%$, medial canthal area $-11.4 \%$, and lateral canthal area $-2.3 \%$. The most frequently used surgical technique for eyelid reconstruction after malignancy excisions was direct closure in 55.7\% of the cases, followed by skin flap transposition $26.1 \%$, Hughes procedure $-9.1 \%$, free full-thickness skin graft for reconstruction of anterior eyelid lamella $-8.0 \%$, and Cutler-Beard procedure $-1.1 \%$.

Entropion was cicatricial in 2 and involutional in 92 cases. The most frequently used surgical procedure for ectropion repair was the Quickert technique $-44.7 \%$, followed by horizontal lid shortening combined with everting sutures $-18.1 \%$, lateral tarsal strip - $17 \%$, Imre technique $-11.7 \%$, free mucous graft $-2.1 \%$, and everting sutures alone $-1.1 \%$ of cases.

Ectropion was cicatricial in 2 cases, paralytic in 6 , and involutional in 58 cases. The most frequent- 
ly used surgical procedure was full-thickness pentagonal flap excision (Bick technique) in 59.1\% of the cases, followed by lateral tarsal strip - $22.7 \%$, KuhntSzymanowski procedure $-10.6 \%$, medial canthoplasty $-4.5 \%$, and others.

Ptosis was congenital in 16 cases and acquired in 27 cases, 22 of which aponeurotic. The most frequently used surgical procedure was resection or plication of levator aponeurosis - 57.2\%, followed by Fasanella-Servat - 33.3\%, and frontalis suspension $-9.5 \%$.

All blepharoplasty surgeries were performed on upper eyelid with a standard technique.

For the whole period only one surgery was performed in a case with floppy eyelid.

\section{DISCUSSION}

This study presented the epidemiologic characteristics of reconstructive eyelid surgeries in the Specialized Eye Hospital - Varna, providing information of prevalence of eyelid tumors, ectropion, entropion, ptosis, and dermatochalasis in ophthalmic surgical practice.

The most common cause of eyelid reconstruction that we found was tumor excision. It presented $50.8 \%$ of all cases of planned surgeries in this study, with prevalence of benign tumors (65.9\%). Asproudis I et al., in a large study which covered a 30-year period in Ioannina, Greece, found $58.8 \%$ of benign tumors, of which seborrheic keratosis - 18\%, nevus $13 \%$, and papilloma - 13\% (8). Ho $\mathrm{M}$ et al. in Hong Kong reported $65.16 \%$ of benign tumors of which nevus $-31 \%$, squamous cell papilloma - $22 \%$, and seborrheic keratosis - 15\% (9). Paul et al. reported 75.9\% of benign tumors in their study in San Francisco, California, with seborrheic keratosis the most common benign neoplasm representing $19.7 \%$ of the cases (10). There is an agreement between our results and all cited publications on the prevalence of benign tumors and an average age of less than 60 years of individuals diagnosed with a benign lesion, but a difference is observed in histological type distribution.

Malignant tumors were diagnosed primarily in patients with an average age over 60 years $(10,11)$, the mean age for patients with malignant lesions was $67.5( \pm 1.6)$ years in Greece $(8)$ and $67.5( \pm 12.06)$ in the present study. In almost all studies, BCC is the most common malignant eyelid tumour. That histolog- ical type comprises about $86 \%$ in Ioannina, Greece (8), 86\% in Lausanne, Switzerland (11), 75\% in Hong Kong (9), and 71.8\% in San Francisco, California (10). In agreement with the above-mentioned data, $\mathrm{BCC}$ is the most prevalent histological type accounting for $85.2 \%$ of the eyelid malignancies in the present study. In contrast, Tan et al., in their study in a tertiary care hospital in Singapore, reported only one case of BCC of the eyelid, making its prevalence less than $0.01 \%$. The low prevalence of BCC of the eyelid is likely due to the difference in skin phototypes between the Asian and Caucasian population (12). In some Asian populations, the proportions of BCC and sebaceous gland carcinoma (SGC) are almost equal, and in some studies, SGC is even the most common malignant eyelid tumor. An Indian study reports the proportion of SGC to be $32.6 \%$, BCC - $29.8 \%$, and SCC $28.1 \%$ (13). In our study only three cases of SGC have been diagnosed. The second most common histological type of eyelid carcinoma was SCC. According to the epidemiological findings of our study, SCC affected 9.1\% of the patients with eyelid cancer on average. Similar were the reports from Ioannina, Greece - 7\%, Lausanne, Switzerland - 8.6\%, and 9.7\% in San Francisco, California $(8,10,11)$.

Lee et al., in their study in South Korea, reported that the second most common eyelid surgery was lid mass excision - $19.1 \%$ and for eyelid reconstruction, the Tenzel semicircular rotational flap, Hughes and reverse Hughes procedures were performed. (14) The most common used technique for eyelid reconstruction after tumor excision is direct closure, in $60.9 \%$ of the cases in this study. There are opinions on the pros and cons of the Hughes procedure in the literature. Emesz $\mathrm{M}$ et al. reported good functional and cosmetic results in $76.4 \%$ of the cases after the Hughes procedure (15), Sommer and Wozniak (16) - in 97.8\%, and Hishmi AM et al. (17) - in 87\%. The Hughes procedure has become less popular in some studies because it is a 2-stage procedure and eyes are closed for 2 to 4 weeks, and contraction of the levator-Muller muscle complex after flap division in the classical Hughes procedure is a common reason for upper eyelid complications (18). In the present study, a modified Hughes procedure was used in $7.8 \%$ of the cases without complications. Also, in accordance with literature, we achieved very good results using 
full-thickness skin graft for reconstruction of the anterior eyelid lamella (19).

The second and third most popular causes for eyelid surgery in that study were entropion and ectropion repair $-18.5 \%$ and $13.0 \%$ of all planned eyelid surgeries, respectively. In $98 \%$ of the cases there was involutional entropion and in $88 \%$ - involutional ectropion. Involutional entropion was more prevalent in females (54.3\%) and involutional ectropion was markedly more prevalent among males (71.2\%). These findings are supported by other studies $(2,3,6)$ and may be explained by the differences of tarsal plate size and axial ocular globe projection between men and women $(20,21)$. The main etiological factors for entropion and ectropion development are lateral and medial canthal tendon laxity, and disinsertion of the lower retractors, therefore surgical techniques with tightening of canthal tendons, horizontal lid shortening, and retractors reinsertion provide the best postoperative results $(22,23,24)$. In the present study, the Quickert procedure was used in $44.7 \%$ of entropion cases, horizontal lid shortening combined with everting sutures - in $18.1 \%$, and lateral tarsal strip in $17 \%$, with very good results. Dulz et al. compared the lateral tarsal strip with everting sutures and the Quickert procedure for involutional entropion and concluded that success rates at 14 months are similar in patients treated with either technique (25). Golan and Lelli found that the combination of the modified Bick quick strip procedure and Quickert sutures provides excellent results for the treatment of involutional entropion (26). The most frequently used surgical procedure for ectropion repair in our study was the Bick technique in $59.1 \%$ of the cases, followed by lateral tarsal strip - 22.7\%. Vahdani et al. compared the functional and anatomical outcomes of lateral tarsal strip (557 cases) with Bick's procedure (87 cases) in the treatment of eyelid malposition and found that Bick's procedure achieved statistically significant better anatomical and functional outcomes compared to lateral tarsal strip although the samples were unequal (27).

Ptosis surgery was relatively rare in that study $8.5 \%$ of all planned eyelid surgeries, with prevalence of acquired aponeurotic ptosis (51.2\%) and an average age of patients - 48.9 years. In contrast, Tan et al. reported that ptosis was the most prevalent reason for eyelid surgery in their study - $19.5 \%$, again with marked prevalence of acquired ptosis and mean patient age of 45.3 years (12). Lim et al., in a retrospective study on 251 patients with ptosis, found that aponeurotic ptosis was the most common type of ptosis $(60.2 \%)$, followed by traumatic $(11.2 \%)$, congenital (10.4\%), etc. (5). In contrast, a study of the epidemiology of ptosis at a teaching hospital in Nepal, where a total of 125 patients were evaluated, showed that congenital ptosis was the most common cause of ptosis in $62.4 \%$ with $37.6 \%$ of the cases being acquired of which only $10.7 \%$ were aponeurotic (28). In the more recent years of our study transcutaneous levator aponeurosis plication was the preferred surgical procedure for involutional ptosis correction. Our results with this technique were in accordance with the excellent results reported by McCulley in $77 \%$ of the cases (29).

Presently, the interest in aesthetic eyelid surgery has been growing. Upper eyelid blepharoplasty, the most common aesthetic surgery performed, may have medical indications, when the drooping skin limits the visual field, or serve a cosmetic purpose following the patient's desire to have a more youthful or aesthetic appearance (30). Blepharoplasty was the most common eyelid surgery reported by Lee et al., accounting for $24.2 \%$ of total eyelid surgeries in their study (14). The incidence of blepharoplasty in the present study was lower $-9.1 \%$, with the mean age of the patients being 53.3 (SD 9.9) years and a significant prevalence of females $-89.1 \%$. We have noted a marked growth of the number of blepharoplasties after 2013.

\section{CONCLUSION}

In conclusion, eyelid reconstruction is an important branch of oculoplastic surgery. We found that tumor excision was the most common reason for planned eyelid surgery and reconstruction. In recent years, the number of blepharoplasties has increased markedly. Numerous surgical procedures exist for eyelid reconstruction, and the surgeon's experience is leading in the choice of a technique.

\section{REFERENCES}

1. Jacobs LC, Liu F, Bleyen I, Gunn DA, Hofman A, Klaver CCW, et al. Intrinsic and extrinsic risk factors for sagging eyelids. JAMA Dermatol. 2014;150(8):836-43. doi: 10.1001/ jamadermatol.2014.27. 
2. Damasceno RW, Osaki MH, Dantas PEC, Belfort R. Involutional entropion and ectropion of the lower eyelid: prevalence and associated risk factors in the elderly population. Ophthal Plast Reconstr Surg. 2011;27(5):317-20. doi: 10.1097/ IOP.0b013e3182115229.

3. Mitchell P, Hinchcliffe P, Wang JJ, Rochtchina E, Foran S. Prevalence and associations with ectropion in an older population: the Blue Mountains Eye Study. Clin Experiment Ophthalmol. 2001;29(3):108-10. doi: 10.1046/j.1442-9071.2001.00412.x.

4. Lee YG, Son BJ, Lee KH, Lee SY, Kim CY. Clinical and demographic characteristics of blepharoptosis in Korea: A 24-year experience including 2,328 patients. Korean J Ophthalmol KJO. 2018;32(4):24956. doi: 10.3341/kjo.2017.0118.

5. Lim JM, Hou JH, Singa RM, Aakalu VK, Setabutr P. Relative incidence of blepharoptosis subtypes in an oculoplastics practice at a tertiary care center. Orbit Amst Neth. 2013;32(4):231-4. doi: 10.3109/01676830.2013.788673.

6. Damasceno RW, Avgitidou, Belfort R, Dantas PEC, Holbach LM, Heindl LM. Eyelid aging: pathophysiology and clinical management. Arq Bras Oftalmol. 2015;78(5):328-31. doi: 10.5935/0004-2749.20150087.

7. Pitheckoff N. Aging in the Republic of Bulgaria. Gerontologist. 2017;57(5):809-15. doi: 10.1093/ geront/gnx075.

8. Asproudis I, Sotiropoulos G, Gartzios C, Raggos V, Papoudou-Bai A, Ntountas I, et al. Eyelid tumors at the University Eye Clinic of Ioannina, Greece: A 30-year retrospective study. Middle East Afr J Ophthalmol. 2015;22(2):230-2. doi: 10.4103/0974-9233.151881.

9. Ho M, Liu DTL, Chong KKL, Ng HK, Lam DSC. Eyelid tumours and pseudotumours in Hong Kong: a ten-year experience. Hong Kong Med J Xianggang Yi Xue Za Zhi Hong Kong Acad Med. 2013;19(2):150-5.

10. Paul S, Vo DT, Silkiss RZ. Malignant and benign eyelid lesions in San Francisco: Study of a diverse urban population. 2011 Jan 1 [cited 2016 Dec 19]; Available from: https://www.scienceopen. com/document?vid=9face $96 \mathrm{c}-\mathrm{ba0b}-4 \mathrm{bd} 5-\mathrm{b} 03 \mathrm{~d}-$ d7833aa44fb4

11. Deprez M, Uffer S. Clinicopathological features of eyelid skin tumors. A retrospective study of
5504 cases and review of literature. Am J Dermatopathol. 2009;31(3):256-62. doi: 10.1097/ DAD.0b013e3181961861.

12. Tan MCJ, Young S, Amrith S, Sundar G. Epidemiology of oculoplastic conditions: the Singapore experience. Orbit Amst Neth. 2012;31(2):107-13. doi: 10.3109/01676830.2011.638095.

13. Sihota R, Tandon K, Betharia SM, Arora R. Malignant eyelid tumors in an Indian population. Arch Ophthalmol. 1996;114(1):108-9. doi: 10.1001/ archopht.1996.01100130104031.

14. Lee J, Lee HK, Lee H, Chang M, Park M, Baek S. Epidemiology of oculoplastic and reconstructive surgeries performed by a single specialist with 15 years' experience at a tertiary center. J Craniofac Surg. 2015;26(4):e308-311. doi: 10.1097/ SCS.0000000000001699.

15. Emesz M, Krall E, Nischler C, Rasp M, Dexl AK, Bauer F, et al. [Hughes' operation and combined procedures]. Ophthalmol Z Dtsch Ophthalmol Ges. 2014;111(5):448-53. doi: 10.1007/ s00347-013-2918-7.

16. Sommer F, Wozniak K. [Lid reconstruction for large lower eyelid defects (extending into canthus) with Hughes flap and skin graft - possibilities and limitations]. Klin Monatsblätter Für Augenheilkd. 2015;232(1):21-6. doi: 10.1055/s-0034-1383015.

17. Hishmi AM, Koch KR, Matthaei M, Bölke E, Cursiefen C, Heindl LM. Modified Hughes procedure for reconstruction of large full-thickness lower eyelid defects following tumor resection. Eur J Med Res. 2016;21(1):27. doi: 10.1186/s40001-016-0221-1.

18. Marcet MM, Lau IHW, Chow SSW. Avoiding the Hughes flap in lower eyelid reconstruction. Curr Opin Ophthalmol. 2017;28(5):493-8. doi: 10.1097/ ICU.0000000000000401.

19. Zlatarova ZI, Nenkova BN, Softova EB. Eyelid reconstruction with full thickness skin grafts after carcinoma excision. Folia Med (Plovdiv). 2016;58(1):42-7. doi: 10.1515/folmed-2016-0006.

20. Bashour M, Harvey J. Causes of involutional ectropion and entropion--age-related tarsal changes are the key. Ophthal Plast Reconstr Surg. 2000;16(2):131-41. doi: 10.1097/00002341-200003000-00008.

21. Heimmel MR, Enzer YR, Hofmann RJ. Entropion-ectropion: the influence of axial globe projection on lower eyelid malposition. Ophthal 
Plast Reconstr Surg. 2009;25(1):7-9. doi: 10.1097/ IOP.0b013e31819128fd.

22. Danks JJ, Rose GE. Involutional lower lid entropion: to shorten or not to shorten? Ophthalmology. 1998;105(11):2065-7. doi: 10.1016/ S0161-6420(98)91126-5.

23. Scheepers MA, Singh R, Ng J, Zuercher D, Gibson $\mathrm{A}$, Bunce $\mathrm{C}$, et al. A randomized controlled trial comparing everting sutures with everting sutures and a lateral tarsal strip for involutional entropion. Ophthalmology. 2010;117(2):352-5. doi: 10.1016/j. ophtha.2009.06.056.

24. Michels KS, Czyz CN, Cahill KV, Foster JA, Burns JA, Everman KR. Age-matched, case-controlled comparison of clinical indicators for development of entropion and ectropion. J Ophthalmol. 2014;2014:231487. doi: 10.1155/2014/231487.

25. Dulz S, Green S, Mehlan J, Schüttauf F, Keserü M. A comparison of the lateral tarsal strip with everting sutures and the Quickert procedure for involutional entropion. Acta Ophthalmol (Copenh). 2019;97(6):e933-6. doi: 10.1111/aos.14093.
26. Golan S, J Lelli G. Involutional entropion repair combining the modified Bick quick strip procedure with Quickert rotational sutures. Orbit Amst Neth. 2019;38(2):130-2. doi: 10.1080/01676830.2018.1497066.

27. Vahdani K, Ford R, Garrott H, Thaller VT. Lateral tarsal strip versus Bick's procedure in correction of eyelid malposition. Eye Lond Engl. 2018;32(6):111722. doi: 10.1038/s41433-018-0048-9.

28. Thapa R, Karmacharya PC, Nepal BP. Etiological pattern of blepharoptosis among patients presenting in teaching hospital. JNMA J Nepal Med Assoc. 2006;45(162):218-22.

29. McCulley TJ, Kersten RC, Kulwin DR, Feuer WJ. Outcome and influencing factors of external levator palpebrae superioris aponeurosis advancement for blepharoptosis. Ophthal Plast Reconstr Surg. 2003;19(5):388-93. doi: 10.1097/01. IOP.0000087071.78407.9A.

30. Bhattacharjee K, Misra DK, Deori N. Updates on upper eyelid blepharoplasty. Indian J Ophthalmol. 2017;65(7):551-8. doi: 10.4103/ijo.IJO_540_17. 